\title{
Inhibitor-Based Therapeutics for Treatment of Viral Hepatitis
}

\author{
Debajit Dey and Manidipa Banerjee* \\ Kusuma School of Biological Sciences, Indian Institute of Technology Delhi, Hauz Khas, New Delhi, India
}

\begin{abstract}
Viral hepatitis remains a significant worldwide threat, in spite of the availability of several successful therapeutic and vaccination strategies. Complications associated with acute and chronic infections, such as liver failure, cirrhosis and hepatocellular carcinoma, are the cause of considerable morbidity and mortality. Given the significant burden on the healthcare system caused by viral hepatitis, it is essential that novel, more effective therapeutics be developed. The present review attempts to summarize the current treatments against viral hepatitis, and provides an outline for upcoming, promising new therapeutics. Development of novel therapeutics requires an understanding of the viral life cycles and viral effectors in molecular detail. As such, this review also discusses virallyencoded effectors, found to be essential for virus survival and replication in the host milieu, which may be utilized as potential candidates for development of alternative therapies
\end{abstract} in the future.

(C) 2016 The Second Affiliated Hospital of Chongqing Medical University. Published by XIA \& HE Publishing Inc. All rights reserved.

\section{Introduction}

Hepatitis is a medical condition wherein the liver undergoes inflammation due to a plethora of reasons, including drug abuse, excessive alcohol abuse, disease conditions etc. ${ }^{1}$

Keywords: Viral hepatitis; Viroporin; Inhibitor.

Abbreviations: CMV, Cytomegalovirus; EBV, Epstein-Barr virus; $\mathrm{HCC}$, HepatocelIular carcinoma; FHF, Fulminant hepatic failure; HBV, Hepatitis B virus; HAV Hepatitis A virus; HCV, Hepatitis C virus; HEV, Hepatitis E virus; HDV, Hepatitis D virus; HAVcr-1/TIM-1, Hepatitis A virus cellular receptor $1 /$ T-cell immunoglobulin and mucin domain 1; IRES, Internal ribosome entry site; $5^{\prime}$-UTR, $5^{\prime}$-Untranslated region; L-SIGN, Liver/lymph node-specific intercellular adhesion molecule-3grabbing integrin; DC-SIGN, Dendritic cell-specific intercellular adhesion molecule-3; GAG, glycosaminoglycan; HSC70, Heat shock cognate 70 protein; HSPG, Heparan sulfate proteoglycans; Grp78, Glucose-regulated protein 78; HSP90, Heat shock protein 90; ORF1, Open reading frame 1 ; NTCP, sodium taurocholate cotransporting polypeptide; cccDNA, covalently closed circular DNA; PK, Protein kinase; NA, Nucleos(t)ide analog; IFN, Interferon; L-HBsAg, Large hepatitis B surface antigen; HDAg, Hepatitis D antigen; PegIFN- $\alpha$, Pegylated IFN- $\alpha$, SVR, Sustained virological response; $\mathrm{HBeAg}$, Hepatitis $\mathrm{B}$ e antigen; HBIg, Hepatitis B immunoglobulin; CHB, Chronic hepatitis B; DAAs, Direct-acting antivirals; ZFNs, Zinc finger nucleases; TALEN's, Transcription activator-like effector nucleases; CRISPR, Clustered regulatory interspaced short palindromic repeats; RNAi, RNA interference; HMA, Hexamethylene amilorides; NN-DNJ, N-nonyl deoxynojirimycin.

Received: 08 June 2016; Revised: 14 September 2016; Accepted: 14 September 2016

DOI: $10.14218 / \mathrm{JCTH} .2016 .00025$

* Correspondence to: Dr. Manidipa Banerjee, Kusuma School of Biological Sciences, Indian Institute of Technology Delhi, Block $1 \mathrm{~A}$, Hauz Khas, New Delhi 110016, India. Tel: +91-11-26597538, Fax: +91-11-26597530, E-mail: mbanerjee@ bioschool.iitd.ac.in
When such inflammation, as manifested in symptoms such as jaundice, nausea, abdominal pain, malaise etc, is caused by viral infections, the condition is referred to as viral hepatitis. ${ }^{1}$ Five hepatotropic viruses - named hepatitis A, B, C, D and $E$ viruses - target liver cells in humans and cause acute and chronic hepatitis. In addition, other viruses such as the adenovirus, cytomegalovirus (CMV) and Epstein-Barr virus (EBV), occasionally cause symptoms of hepatitis. ${ }^{2}$

While an acute infection in healthy, immunocompetent individuals is cleared spontaneously, complications like cirrhosis, hepatocellular carcinoma (HCC) and fulminant hepatic failure (FHF) may arise in immunocompromised individuals, due to associated secondary reasons such as existing infections, alcohol abuse, or genetic predisposition. ${ }^{1,3} \mathrm{HCC}$, the third leading cause of cancer-related deaths worldwide, ${ }^{4}$ is closely associated with hepatitis B virus (HBV) infections. Even though the therapeutic strategies devised till date are targeted towards chronic infections, treatment options become severely limited for advanced stage patients. ${ }^{1}$ In addition, current medications have significant side-effects, which poses an issue with disease management. Hence, there is an urgent requirement for safer and more potent drugs.

This review will focus on the therapeutics currently available for treating viral hepatitis of all forms. In addition, the potential of new therapeutics and targeted inhibitor-based therapies against viral membrane-penetrating peptides and viroporins, a group of virally encoded proteins involved in facilitating replication and other specific steps in the viral life cycle, are also discussed.

\section{Life cycle of hepatotropic viruses}

Life cycles of the known hepatotropic viruses - particularly $A$, $B, C$ and $E-$ have been studied in significant detail. Although the lack of appropriate cell culture systems, and the slowgrowing nature of the virus, has hampered studies, considerable information is available on the entry, replication and exit mechanisms of these viruses, and on specific hostinteracting partners for each virus. Hepatitis A virus (HAV) is thought to associate with a cell-surface protein receptor, HAVcr-1/TIM-1 (Hepatitis A virus cellular receptor 1/T-cell immunoglobulin and mucin domain 1), a member of the immunoglobulin superfamily, by which it gains entry into host cells. ${ }^{5}$ Post-entry, translation of the positive-sense RNA genome by the host ribosomal machinery, mediated via the presence of an internal ribosome entry site (IRES) encoded in the 5'-untranslated region (UTR) of viral RNA, results in the production of a large viral polyprotein. The polyprotein is cleaved into structural (VP1-2A, VP2, VP3, VP4) and nonstructural proteins $(2 B, 2 C, 3 A, 3 B, 3 C, 3 D)$ as well as intermediates ( $3 C D, 2 B C$ etc) by a virally-encoded protease $3 C^{\text {pro }}$. Following the cleavage event, the viral RNA replicase 
synthesizes a minus-sense strand corresponding to the viral RNA genome, which serves as a template for the production of multiple plus-sense strands. Meanwhile, structural proteins assemble to form virions, which package a majority of the plus-sense RNA generated during replication. Two specific cleavage events result in generation of mature infectious virions - the VP1-2A precursor cleavage and the VP4/VP2 junctional cleavage. ${ }^{6-11}$ Virions are subsequently released from the apical membrane of infected hepatocytes. ${ }^{11}$

Entry of hepatitis $\mathrm{C}$ virus (HCV) into target host cells is a multistep event, requiring several host components. The cellular receptors and surface molecules, which are thought to be involved in this process, include the C-type lectins liver/ lymph node-specific ICAM-3-grabbing integrin (L-SIGN) and dendritic cell (DC)-specific intercellular adhesion molecule-3 (ICAM-3)-grabbing nonintegrin (DC-SIGN), glycosaminoglycans (GAGs), claudins 6 and 9 and CD-81.12-14 Binding to cellular receptor(s) is primarily mediated by the viral envelope proteins E1 and E2. Post-entry, the virus nucleocapsid disassembles releasing the plus-sense RNA genome in the cell cytosol, which acts as a template for 5'-IRES mediated translation. The single HCV polyprotein generated during translation, like the corresponding HAV polypeptide, also undergoes protease mediated co- and post-processing to yield the entire repertoire of viral structural and non-structural proteins. ${ }^{14}$ During HCV infection, membranous webs ${ }^{14-16}$ are formed, which are sites for RNA replication (NS5B mediated) and translational post-processing events. While the endoplasmic reticulum (ER) serves as the site for the formation of the viral nucleocapsid, envelope formation and final virus maturation occurs in the Golgi. Matured virions are exocytosed into the extracellular space. ${ }^{14}$

The life cycle of hepatitis $E$ virus (HEV) is not well understood, primarily due to the non-availability of an appropriate cell culture system. Studies have shown the possible involvement of heat shock cognate 70 protein (HSC70) and heparan sulfate proteoglycans (HSPGs) in the initial attachment of HEV to its target cells, while the final entry is mediated by a yet unknown receptor. ${ }^{17,18}$ Several host factors, such as glucose-regulated protein 78 (Grp78) and heat shock protein 90 (HSP90), are also thought to be involved in viral entry. ${ }^{19,20}$ Capsid uncoating and RNA genome release in the cytosol is closely followed by translation of the viral open reading frame (ORF) 1, which encodes the entire non-structural cassette. ${ }^{21,22}$ Multiple copy synthesis of the positive-sense RNA genome is mediated by virus-encoded RNA-dependent RNA polymerase via a negative-sense RNA intermediate. The viral ORF2 encodes the capsid protein, which associates with the progeny viral genomes to form the nucleocapsids, followed by the intracellular transport and release of mature virions. ${ }^{21,22}$ It has been postulated that the viral ORF3 encodes a protein involved in intracellular trafficking process. ${ }^{21,22}$

HBV, unlike other hepatotropic viruses, has a distinct mechanism for propagation within its host. Cellular entry of incoming particles via endocytosis is initiated through interactions with HSPGs, ${ }^{23,24}$ followed by that with the sodium taurocholate cotransporting polypeptide (NTCP). ${ }^{24,25}$ After gaining access to the cytosol, the virus travels to the nuclear pore complex, where the DNA genome is released into the nucleus. The partially double-stranded DNA genome is subsequently converted into a covalently closed circular DNA (ccCDNA) form which associates with histones and other nuclear proteins. Within the nucleus, transcription events lead to the production of mRNA, encoding for the reverse transcriptase and the nucleocapsid (pregenomic). In addition, transcripts encoding the surface antigens (subgenomic) are also produced. Both pre- and subgenomic transcrpits are transferred to the cytosol. Surface protein synthesis, to generate core and subviral particles, occurs in the ER. Translation products (viral polymerase and core protein) of the pregenomic RNA associate with protein kinases (PKs), ${ }^{26,27}$ $\mathrm{HSPs}^{27,28}$ and pregenomic RNA to yield mature core particles, which are either released from infected cells, or are recirculated to the nucleus to maintain the cccDNA level. ${ }^{25,28}$ Interestingly, while subviral particles are released via the secretory pathway involving the Golgi and ER, mature core particles are released through multivesicular particles. ${ }^{25}$

Although not much is known regarding the cellular entry process of hepatitis D virus (HDV), studies have suggested similarities with the HBV entry pathway involving interaction of HSPGs and NTCPs with the viral large hepatitis B surface antigen (L-HBsAg; pre-S1 domain). ${ }^{24,29}$ Post-entry, transfer of the RNA genome to the nucleus is facilitated by the virallyencoded hepatitis D antigen (HDAg). ${ }^{30}$ Within the nucleus, host RNA polymerases initiate genome replication, which proceeds via a rolling circle mechanism. ${ }^{30}$ Subsequent transcriptional and translational events lead to the production of the large delta antigen which undergoes prenylation prior to association with progeny viral genomes. Subsequent assembly and viral release requires assistance from HBV. ${ }^{30}$

\section{Current treatment scenario}

\section{HAV}

Currently there are no specific treatment options available for HAV. Infected individuals usually receive symptomatic treatment, with liver transplantation being the only viable option in cases of FHF. $^{11}$ Vaccination, with inactivated HAV virions, is fairly effective for conferring protection against all prevalent strains of the virus found in the human population. ${ }^{31,32}$ Vaccination with attenuated virions has also been employed, but has met with limited success. ${ }^{33}$ In spite of active vaccination efforts, however, the number of clinical cases of HAV reported is quite high, being $\sim 1.5$ million worldwide. ${ }^{11}$

\section{$\mathrm{HCV}$}

Due to the mostly asymptomatic nature of acute HCV infection, treatment options are limited. However, studies have reported that interferon-based treatment at an early stage might be helpful. ${ }^{34}$ Individuals exhibiting HCV RNA and antibodies at detectable levels in their blood after more than 6 months post-infection are considered to be cases of chronic $\mathrm{HCV}$ infection. A combination therapy of ribavirin and PegIFN- $\alpha$ (pegylated interferon $\alpha$ ), for a duration of either six months or one year, was the accepted treatment regimen for chronic cases of HCV infection up until 2011. ${ }^{35}$ However, achievement of a sustained virological response (SVR), which is the key to cure, was observed to vary between genotypes and populations. ${ }^{36}$ Western European patients infected with HCV genotype 1 reportedly achieve a higher SVR (50\%) than the North American patient population (40\%). The SVR achieved with this treatment in case of patients infected with genotypes 2, 3, 5 and 6 was observed to be higher in general compared to genotype 1-infected patients (SVR of up to $80 \%$ ). In particular, genotype 2 was the found to be 
Dey D. et al: Inhibitors for viral hepatitis

most susceptible (SVR > 80\%). ${ }^{36}$ Direct-acting antivirals (DAAs) such as telaprevir and boceprevir (first-wave, first generation), which target the HCV NS3-4A serine protease, were introduced in 2011 for treating infections caused by HCV genotype $1 .^{37}$ Phase III clinical trials on treatmentnaïve patients found that administration of telaprevir and boceprevir in conjunction with ribavirin and Peg-IFN- $\alpha$ (triple-combination) was effective in achieving a SVR in the range between $65 \%$ and $75 \% .{ }^{37}$ However, this treatment regimen comes with its own set of disadvantages, including significant side-effects and not being cost-effective in the case of patients with advanced fibrosis. ${ }^{37}$ Since 2011, the following DAAs have been approved which can be used either independently or in combination with Peg-IFN- $\alpha$ and/or ribavirin. These DAAs are (a) sofosbuvir (nucleotide analogue), (b) simeprevir (NS3-4A protease inhibitor), (c) daclatasvir (NS3-4A protease inhibitor), (d) paritaprevir (NS3-4A protease inhibitor), (e) ombitasvir (NS5A inhibitor), (f) asunaprevir (NS3-4A protease inhibitor), (g) grazoprevir (NS3$4 \mathrm{~A}$ protease inhibitor) and (h) elbasvir (NS5A replication complex inhibitor). ${ }^{35}$ The rate of SVR achieved depends on the combination used, the genotype, the presence of resistant strains and the disease severity. Finally, attempts to create an effective vaccine against HCV have not been successful till date due to the extreme sequence variation of the virus genome.

\section{HEV}

Acute HEV infections in immunocompetent individuals usually culminate in spontaneous clearance of the virus after a certain time period. However, in severe cases leading to decreased liver functioning, administration of ribavirin was found to help in prompt clearance of the virus and inhibition of further liver damage. ${ }^{38}$ It remains unclear if ribavirin intake can arrest the progress towards complete liver failure (fulminant hepatitis). Till date, liver transplantation from appropriate donors remains the only choice for such patients. ${ }^{39}$ For treatment of transplantation patients suffering from chronic infection with HEV, the following course of action is usually undertaken post-transplantation. The first step involves the reduction of immunosuppression, which has been shown to have a $25 \%$ clearance rate. ${ }^{40}$ If this is unsuccessful, the next step usually involves monotherapy with ribavirin for an initial period of 90 days. ${ }^{39,41,42}$ Administration of Peg-IFN- $\alpha$ is also an option; however, due to its many side-effects and complications in solid organ transplantation recipient patients, it is not preferred. ${ }^{39} \mathrm{HEV}$ infection in pregnant women is associated with significant complications like stillbirths, abortions, premature distribution and maternal or fetal death. ${ }^{43}$ Interestingly, significant differences exist in the severity of complications caused by HEV infection in diverse endemic populations. For instance, while the infection typically has severe outcomes in pregnant women from northern India, it follows a fairly benign course in populations from Egypt and western countries. ${ }^{44,45}$ Studies suggest that poor prenatal care and nutrition may constitute major contributory factors for such severe outcomes in selected populations. ${ }^{46}$ Efforts are ongoing to develop an effective vaccine against HEV, and currently a promising candidate (trade name: Hecolin) is in Phase IV of clinical trials (clinicaltrials.gov database).
HBV

As with other forms of hepatitis, acute infections with HBV are treated symptomatically 47,48 and no specific treatment regimen exists. However, patients who develop acute liver failure resulting from severe HBV infection are administered oral anti-HBV medication. ${ }^{49}$ The major emphasis so far is on treatment of chronic infection of HBV. The currently approved drugs are interferons, Peg-IFN-2a for adults and IFN- $\alpha-2 b$ for children, and nucleotide/nucleoside analogues or NAs (nucleoside analogues: lamivudine, entecavir, emtricitabine, telbivudine; nucleotide analogues: adefovir, tenofovir). ${ }^{50,51}$ Due to their high barrier to development of resistance, tenofovir and entecavir are used as the first-line drugs for treatment. ${ }^{50,51}$ Other analogues like lamivudine, adefovir and telbivudine are only prescribed when the more potent drugs are either not appropriate or not available. ${ }^{50,51}$ This is due to fact that these drugs either have a low barrier to resistance (telbivudine), are less efficacious (adefovir) or have been shown to develop resistance over long-term usage (lamivudine). ${ }^{50}$ Interferons are utilized as they enhance the host antviral immune response. ${ }^{50,51}$ The therapeutic strategy usually involves two specific routes applicable to chronic hepatitis $B$ (CHB): (i) a short treatment (1 year) with Peg-IFNs or NAs and (ii) treatment with NAs on a long-term basis.

i. Peg-IFN-based therapy is prescribed for a period of 48 weeks for patients who have the best possibility for $\mathrm{HBe}$ seroconversion (absence of $\mathrm{HBeAg}$ in serum and presence of anti-HBe antibodies) in order to obtain an off-treatment response. ${ }^{50,52}$ Combinations of Peg-IFN with NAs like lamivudine or telbivudine are not recommended because of a low off-treatment response for the former and due to recipients developing polyneuropathy for the latter. ${ }^{53} \mathrm{HBeAg}$-positive patients who undergo serotype conversion to anti-HBe can be treated with NAs for some time. However, it is not possible to define exactly the timespan before treatment initiation since it is based on the time taken to undergo serotype conversion and treatment continuation postseroconversion. ${ }^{50}$ A stable off-treatment response in $(40-80) \%$ of treated individuals has been observed ${ }^{54}$ when treatment is continued for about 12 months post serotype conversion to anti-HBe.

ii. The second strategy applies to those individuals who do not undergo seroconversion and have HBV-related liver cirrhosis. ${ }^{50}$ Entecavir and tenofovir are used, however, the long term effects of the use of these drugs is not known. Current data shows that monotherapy for 3 years or more ensures remission in majority of treated patients. ${ }^{55-57}$

Patients undergoing liver transplantation due to HBVrelated $\mathrm{HCC}$ or decompensated liver cirrhosis undergo a pre-transplantation treatment regime with a potent NA having a high resistance barrier in order to reduce the viral DNA levels to a minimum before transplantation. ${ }^{58,59}$ Posttreatment, a combination of adefovir and/or lamivudine with hepatitis B immunoglobulin (HBIg) has been found to be effective (graft rejection rate of less than 10\%). ${ }^{59,60}$ Given the treatment scenario and the complications associated, prevention of HBV infections is a priority. An effective vaccine against HBV exists and is administered 3-4 times over a 6 month period. ${ }^{58}$ 
Dey D. et al: Inhibitors for viral hepatitis

\section{HDV}

Till date, there are no known effective therapeutic strategies available for treatment of either the acute or chronic forms of HDV infection. ${ }^{61}$ Studies have shown that long-term treatment with Peg-IFN $\alpha$ helps in clearance of the virus in about $25 \%$ of the cases. ${ }^{61}$ The efficacy is similar when interferon is administered in combination with adefovir. ${ }^{61}$ Thus, in the absence of an effective antiviral therapy, liver transplantation is the only option for patients suffering from liver damage due to chronic infection. There are no commercially available vaccines against HDV; however, the vaccine available for HBV can be used to prevent co-infection of HBV and HDV. ${ }^{61}$

\section{Viral inhibitors and their mechanism of action}

Based on the current knowledge of the molecular details of viral life cycles and virus-host interactions, there can be several targets for designing inhibitors. The following classes of inhibitors are discussed below: (i) viral polymerase inhibitors, (ii) viral protease inhibitors, (iii) CyPA inhibitors and (iv) host lipid modulators.

i. Viral polymerases play integral roles in the virus life cycle by carrying out replication and transcription of the viral genome and are therefore targets for inhibitor therapy. Inhibitors in current use against viral polymerases can be classified as (a) NAs and (b) non-NA polymerase inhibitors. NAs are used in the treatment of several viral diseases and are one of the first class of inhibitors identified. ${ }^{62}$ Upon their uptake by cells, nucleoside analogues undergo a set of three phosphorylation events, producing nucleoside triphosphates that lack a 3 '-OH group on the deoxyribose sugar. These inhibit the replication process by chain termination and stalling replication-associated polymerases. NAs have a similar mechanism of action, with the distinction that they essentially bypass the phosphorylation steps. ${ }^{63}$ Several such drugs, like emtricitabine, lamivudine, tenofovir, entecavir, stavudine, abacavir etc, are available for treatment of human immunodeficiency virus (HIV). Several analogues are also being used in treatment of chronic HBV and HCV infections, as mentioned in the previous sections. Other effective inhibitors include favipiravir, which can successfully inhibit both negative- and positive-sense RNA viruses and has been approved for the treatment of influenza virus in Japan, and BCX4430, which shows similar inhibitory effects. ${ }^{62}$ These compounds have significant toxicity issues and side-effects due to the replication inhibition being primarily non-specific. In addition, resistant phenotypes are often encountered, which decreases treatment efficacy. ${ }^{62}$ (b) Non-NA polymerase inhibitors, on the other hand, are targeted to bind to sites other than the active site on viral polymerases, and induce conformational changes, leading to down-regulation in activity. In this class, HIV-1 reverse transcriptase inhibitors like nevirapine, delavirdine and efavirenz are well known. These primarily inhibit HIV-1 replication by binding to the p66 subunit of the p66/p51 heterodimeric complex. ${ }^{64}$ Four different classes of non-NA polymerase inhibitors are currently undergoing clinical trials for treatment of HCV genotype 1: Thumb I (BI-207127), Thumb II (GS-9669, filibuvir and VX-222), Palm I (ABT-333, ABT-072 and setrobuvir) and Palm II (nesbuvir, tegobuvir and IDX-375).
The nomenclature is based on the structural organization of the HCV NS5B. ${ }^{65}$

ii. Proteases play an essential role in the life cycle of many viruses, making them essential targets for inhibitor design. The HIV protease cleaves the viral polyproteins into individual components, and inhibiting the protease can effectively block viral replication. ${ }^{66}$ Currently, the United States' Food and Drug Administration has approved several inhibitor drugs which belong in this category, namely saquinavir, atazanavir, darunavir, fosamprenavir, indinavir, nelfinavir, lopinavir, ritonavir and tipranavir. While inhibitors against the NS3-4A serine protease of $\mathrm{HCV}$, such as boceprevir and telaprevir, were used initially, their usage has been discontinued since a more effective treatment regimen of simeprevir, asunaprevir and paritaprevir are now available, as mentioned earlier herein. Several $3 \mathrm{C}$ or $3 \mathrm{C}$ like proteases exist in picornaviruses, coronaviruses and noroviruses. ${ }^{62}$ In fact, rupintrivir (an irreversible $3 C$ protease inhibitor), which was originally designed to treat rhinovirus infections, also displays inhibitory activity against the above mentioned virus families. ${ }^{67}$ Lastly, treatment regimen usually involves combination therapy due to chances of emergence of resistant phenotypes. ${ }^{62}$

iii. Cyclophilin A (CyPA) belongs to a ubiquitous, hostencoded protein family (peptidyl-prolyl cis/transisomerases), which helps in folding and trafficking of other host proteins. ${ }^{68}$ CyPA was found to interact with the non-structural protein NS5A ${ }^{69,70}$ of $\mathrm{HCV}$ and the capsid protein p24 of HIV. ${ }^{71}$ Presently, two drugs that inhibit CyPA, namely alisporivir and SCY-635, are in use. Both drugs are derivatives of the original immunosuppressive drugs sanglifehrin $A$ and cyclosporine $A{ }^{62}$

iv. Since host lipid metabolism is essential for viral replication, ${ }^{72}$ compounds which specifically alter this process have been found to inhibit viral infections. Perhaps the most notable of this class of inhibitors are the statins, which block cholesterol biosynthesis by obstructing the activity of 3-hydroxy-3-methyl-glutaryl coenzyme A. ${ }^{62}$ However, although this class of inhibitors have shown positive results in vitro against several pathogens like HIV and HCV, significant contradictions were encountered during in vivo studies. ${ }^{62}$ The indole derivative arbidol interferes with virus membrane fusion and entry of enveloped viruses. Although it has been approved in China and Russia for treating respiratory pathogens like influenza virus, and in vitro data on HBV, Chikungunya and HCV appears encouraging, data related to the in vivo efficacy of this drug is lacking. ${ }^{62}$ LJ001 is another lipid modulator that induces membrane lipid oxidation and interferes with virus membrane fusion. It was found to be fairly effective against enveloped viruses such as influenza, filoviruses and $\mathrm{HIV}^{73}$ but its poor physiological stability and requirement of light for optimal activity makes it rather unsuitable for further development. Derivatives of LJ001 have since been produced with improved characteristics. ${ }^{62}$ Squalamines are compounds that interact with the host membrane and alter the cellular microenvironment to make it unsuitable for virus propagation. This compound has also been successful in phase II trials for retinal vasculopathies and cancer, warranting its further development. ${ }^{62}$ 
Dey D. et al: Inhibitors for viral hepatitis

Several new targets have been identified in HBV against which inhibitors have been designed, and many are presently at different stages of development or in clinical trials. These include potent polymerase inhibitors, entry inhibitors, cccDNA inhibitors, nucleocapsid assembly inhibitors, inhibitors of viral gene expression and HBsAg release inhibitors. Equally effective but safer derivatives of tenofovir and entecavir (tenofovir alafenamide and besofovir) have shown promising results in randomized phase III trials with respect to bone and renal safety profiles. ${ }^{74-77}$ Besofovir is another drug which is being tested as an alternative to entecavir. ${ }^{78,79}$ Myrcludex-B is an engineered lipopeptide that effectively blocks NTCP receptors, the entry points for incoming HBV virions. ${ }^{80}$ Mouse model studies with Myrcludex-B have shown a reduction in both cccDNA levels and virus spread, and phase II clinical trials are currently ongoing. ${ }^{80}$ Three types of site-specific DNA binding proteins are being engineered to target ccCDNA: zinc finger nucleases (ZFNs), transcription activator-like effector nucleases (TALENs) and clustered regulatory interspaced short palindromic repeats (CRISPR)-Cas endonucleases. ${ }^{81}$ In vitro studies in cells have shown that all three systems can deactivate cccDNA by either site-specific cleavage, ${ }^{82}$ by introducing frameshifts in viral $\mathrm{ORFs}^{83}$ or by specific disruption (CRISPR-Cas). ${ }^{84,85}$ Disubstituted sulphonamides (CCC-0975 and (CC-0346) have also been identified; these have been shown to prevent the formation of ccCDNA from relaxed circular DNA in vitro. ${ }^{86}$ Compounds that prevent the encapsidation of viral pregenomic RNA, such as sulfamoylbenzamide and phenylpropenamide derivatives, also constitute attractive options for therapy. ${ }^{87,88}$ These are effective against both NA-resistant and wild-type HBV. ${ }^{89}$ Inhibition of viral gene expression using RNA interference (RNAi) is a very attractive option since low levels of viral antigens will allow the immune system to recover. ARC-520, one such drug under development, has shown promising results in vitro. ${ }^{90,91} \mathrm{~A}$ nucleic acid polymer, REP 2055, has been shown to be able to inhibit the release of HBsAg from infected hepatocytes in in vivo studies. ${ }^{92}$ Finally, recent studies have also shown that the HBV RnaseH, which is critical for virus replication, can also be an important drug target. ${ }^{93,94}$ As in the case of HBV, novel drug targets have been identified in other hepatotropic viruses as well (Table 1 ).

\section{Viroporins as promising inhibitor targets}

The virus life cycle begins when it infects a suitable host in order to make multiple copies of itself by utilizing the host machinery. The process from infection to generation of progeny virions is executed as a series of very well coordinated steps and involves attachment, entry, uncoating, replication-transcription-translation of genetic material, assembly and egress. The virus genome encodes a limited number of proteins, all of which can be categorized primarily into structural and non-structural proteins. While structural proteins generate the virus capsid, non-structural proteins are produced after infection and are usually not a part of the capsid. ${ }^{74,95}$ Recently, a set of viral proteins have been identified which play essential roles in the virus life cycle, primarily through their ability to interact with and penetrate cellular membranes. This class of multifunctional proteins, designated viroporins, form pores or channels in cellular membranes, which directly or indirectly facilitate the intracellular survival of the virus. ${ }^{96}$ It has been suggested that the ability of viroporins to alter ionic concentration and remodel host cell membranes, enhances viral uncoating, replication and egress. ${ }^{96}$ Usually viroporins are small peptides (up to 100 amino acids) and contain one or more transmembrane domain(s). Formation of pores or channels in cellular membranes is facilitated by homo-oligomerization between viroporins. Oligomerization levels can range from dimeric association (e.g. in HAV 2B) ${ }^{97}$ to large heptameric assemblies (e.g. in HCV p7). ${ }^{96}$ Till date, several viroporins have been identified and functionally characterized for both enveloped and non-enveloped viruses (Fig. 1, Table 2). Some of the well-known examples are influenza A virus M2, HIV-1 Vpu, picornavirus $2 \mathrm{~B}$ and $\mathrm{HCV}$ p7. ${ }^{96}$

The central role of viroporins in facilitating several steps in the life cycle of viruses suggests that this class of viral proteins are promising candidates for development of inhibitor-based therapeutics. In fact, small molecule inhibitors have been successfully designed and tested against certain viroporins with encouraging outcomes; drugs such as amantadine and rimantadine have been shown to be effective in inhibiting the ion channel activity of M2. ${ }^{98,99}$ Interestingly, several influenza strains, with specific point mutations (Leu26Phe, Ser31Asn, Val27Ala, Ala30Thr, Leu28Phe Ser31Asn and Gly34Glu) which cause resistance to M2 inhibitors have been identified recently. ${ }^{79}$ These mutations most likely affect the drug binding sites of the M2 channel by altering binding pocket hydrophobicity or the overall conformation of the channel. The most prevalent point mutation is Ser31Asn, which has been identified in the H1N1, H7N9 and H1N5 strains of the virus. Attempts are currently being made to synthesize inhibitors against the resistant strains using derivatives of $M 2$ inhibitors. Although novel effective derivatives have been obtained against several of the mutations, those against point mutations at Asn31 have proven to be difficult to generate. ${ }^{98}$

Hexamethylene amilorides (HMA), and its derivatives (e.g. BIT225), have been found to be effective in blocking Vpu

Table 1. List of potential inhibitors against viral proteins currently under investigation

\begin{tabular}{llll}
\hline Virus & Inhibitor & Target & Reference \\
\hline HCV & Hydroxyanthraquinone & NS3 helicase & Furuta et al, 2015 \\
HBV & Hydroxlate tropolones & Ribonuclease H & Hu et al, 2013 \\
& Lu et al, 2014 & Liu et al, 2014 \\
HAV & Niranthin & Not known & Jiang et al, 2015 \\
& AZD1480 & JAK2 & Kanda et al, 2015 \\
& Sirtinol & Sirtuin & Koh et al, 2015 \\
HDV & Lonafarnib & Viral prenylation & \\
\hline
\end{tabular}


Dey D. et al: Inhibitors for viral hepatitis

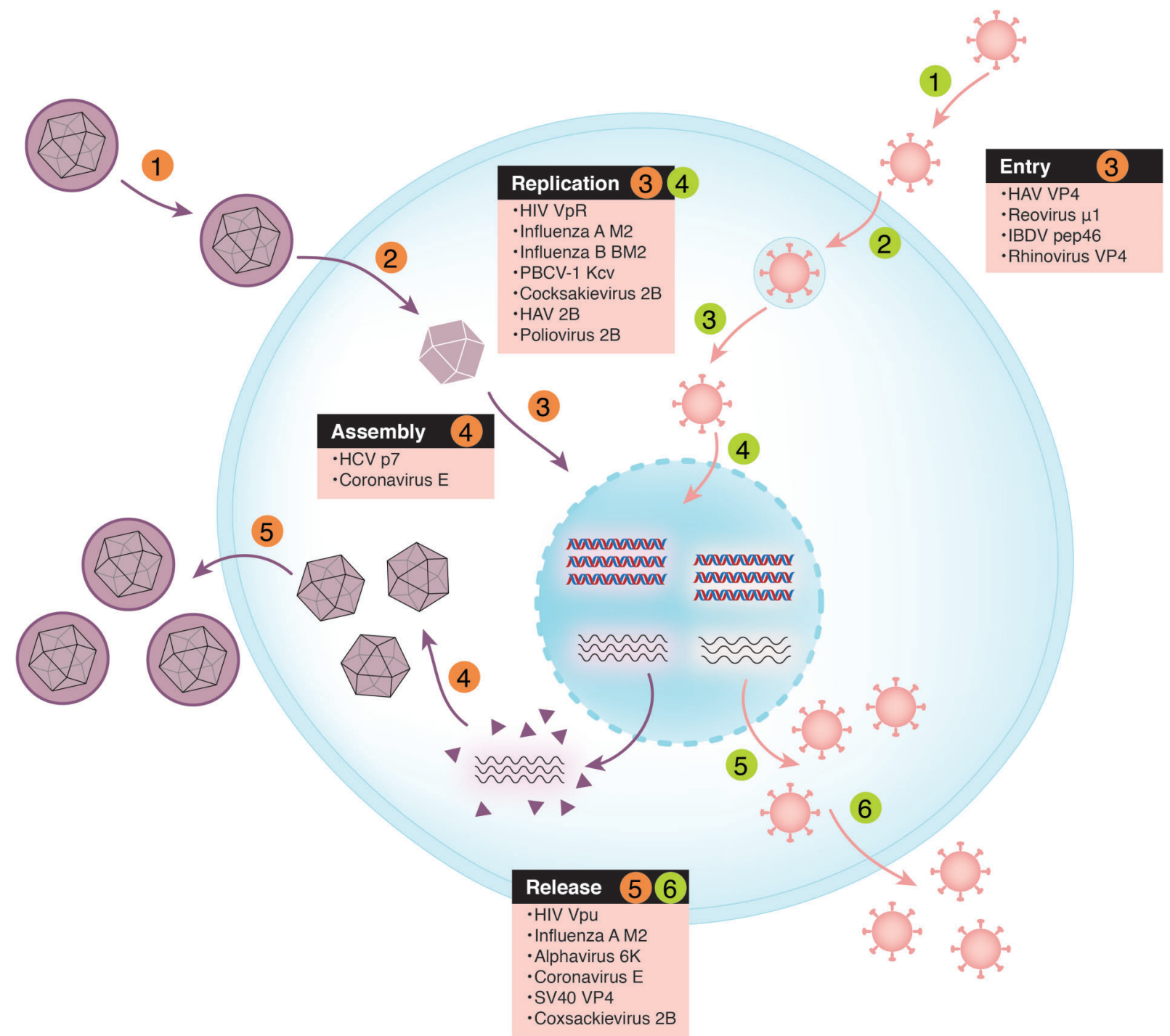

Fig. 1. General schematic showing various steps in the life cycle of enveloped and non-enveloped viruses and the involvement of viroporins or viral membrane penetrating peptides. In the case of enveloped viruses, steps 1, 2, 3, 4 and 5 represent attachment, entry, uncoating and replication, assembly and egress, respectively. For non-enveloped viruses, steps $1,2,3,4,5$ and 6 represent attachment, entry, release from the intracellular vesicle, uncoating and replication, assembly and egress processes.

channel activity and is thought to bind in the channel lumen. The BIT225 HMA derivative is currently undergoing clinical trials. ${ }^{98}$ This inhibitor is specific to HIV-1 and till date no resistant strains have been reported.

Coronavirus-encoded $\mathrm{E}$ peptides are also effectively blocked by HMA, as has been observed in electrophysiology studies using HEK-293T cells. ${ }^{98}$ Amantadine is also capable of inhibiting activity, but the effect requires significantly higher concentrations. ${ }^{98}$

Adamantanes, alkyl imino-sugars and HMA were identified as $\mathrm{HCV}$ p7 blockers based on protein based in vitro assays. ${ }^{98,100}$ However, studies reported inconsistency in efficacy data, which was preliminarily due to the genotypic/subtypic differences between the p7 channels, even though compounds like rimatadine and $\mathrm{N}$-nonyl deoxynojirimycin (NN-DNJ) exhibited wide-spectrum activity amongst genotypes. ${ }^{98}$ Availability of high resolution structural data and in silico docking studies helped in unravelling the mechanism of action of these inhibitors. ${ }^{80} \mathrm{NN}-\mathrm{DNJ}$ was found to interfere with p7 oligomerization via interaction with a specific phenylalanine residue at the $25^{\text {th }}$ position. Interestingly, the inhibitory activity of adamantane was found to be due to binding of the inhibitor at a peripheral site (Leu20) that is exposed on the membrane, separate from the NN-DNJ binding site. ${ }^{98}$ The disparate binding sites for inhibitors provides the possibility of using a combination therapy approach to treat resistant strains. Current drug development efforts typically use a combination of rational and high-throughput approaches. This has resulted in identification of compounds against resistant p7 phenotypes with higher potency at minimal concentrations. ${ }^{98}$

Current interest and the pool of available data leads to the conclusion that viroporin-based therapeutic approaches will subsequently play an important role in treating clinically 
Dey D. et al: Inhibitors for viral hepatitis

Table 2. List of reported viral membrane penetrating peptides and their role in the virus life cycle

\begin{tabular}{llll}
\hline Name & Length (residue length) & Virus & Stage of life cycle \\
\hline Vpu & $77-86$ & HIV-1 & Egress $^{106}$ \\
Vpr & 96 & HIV-1 & Replication $^{116}$ \\
M2 & 97 & Influenza A & Replication and egress $^{108}$ \\
BM2 & 115 & Influenza B $^{\text {a }}$ & Replication $^{95}$ \\
E & $76-109$ & Coronavirus & Assembly and egress $^{109}$ \\
3a & 274 & Coronavirus & Egress $^{110}$ \\
KcV & 94 & PBCV-1 & Replication $^{111}$ \\
VP4 & 23 & HAV & Entry $^{101}$ \\
VP4 & 125 & SV40 & Egress $^{112}$ \\
2B & 251 & HAV & Replication $^{97}$ \\
2B & $97-99$ & Coxsackievirus & Replication and egress $^{113}$ \\
2B & 97 & Poliovirus & Replication $^{114}$ \\
6K & $58-61$ & Alphavirus & Egress $^{115}$ \\
P7 & 63 & HCV & Assembly $^{107}$ \\
$\mu 1$ & 29 & Reovirus & Entry $^{117}$ \\
Pep46 & 46 & IBDV & Entry $^{118}$ \\
\hline
\end{tabular}

relevant human pathogens. The approaches towards designing inhibitors for treatment of HCV and its resistant phenotypes can also be extended to the other hepatotropic viruses. In fact, recent work from our laboratory has characterized the membrane activity of capsid component VP4 and nonstructural protein $2 \mathrm{~B}$ from HAV. ${ }^{97,101}$ Utilizing a combination of biophysical studies, MD simulation and electron microscopy, it was shown that VP4 forms discreet pores of $5 \sim 9$ $\mathrm{nm}$ in artificial membranes. Our data thus indicates that VP4 is a membrane penetrating peptide which may allow HAV to escape from endosomes and gain access to the cellular cytosol. The potentially critical role played by VP4 in HAV entry makes it an important target for design of inhibitors.

We further investigated the non-structural $2 \mathrm{~B}$ protein of $\mathrm{HAV}$, which was found to contain a stretch of 60 residues in its $\mathrm{C}$-terminus, and which has viroporin-like activity. ${ }^{97} \mathrm{~A}$ combination of crosslinking studies, biophysical assays and simulation was employed to determine that $2 \mathrm{~B}$ probably forms dimers and generates $\sim 3 \mathrm{~nm}$ pores in membranes. The resulting alteration of membrane permeability is thought to be essential for HAV replication. It is probable that inhibition of the membrane activity of $2 \mathrm{~B}$ would negatively impact the viral replication process. Thus, a treatment regimen against HAV, which includes a combination therapy targeting VP4 and $2 \mathrm{~B}$, could be a very promising and effective approach.

\section{Conclusion and future perspectives}

Given the essential roles played by viroporins and viral membrane penetrating peptides in enhancing several aspects of the virus life cycle, targeted inhibitor therapy holds promise for development of virus-specific drugs. Establishing the commonalities between the structures and functions of these membrane active components might make it easier to design small molecule inhibitors. Finally, given the promise of p7-based therapy against $\mathrm{HCV}$, it is essential to pinpoint such potential candidates in other hepatotropic viruses, in order to expand therapy options against chronic and acute viral hepatitis.

\section{Acknowledgement}

This work was supported by a grant from the Department of Biotechnology, India (BT/PR7439/MED/29/676/2012). D.D. was supported by a research fellowship from the Council of Scientific and Industrial Research (CSIR), India.

\section{Conflict of interest}

None

\section{Author contributions}

Wrote the manuscript (DD, MB).

\section{References}

[1] Wood NJ. Viral hepatitis: progress and promise. Nat Rev Gastroenterol Hepatol 2011;8:239. doi: 10.1038/nrgastro.2011.50.

[2] Adams DH, Hubscher SG. Systemic viral infections and collateral damage in the liver. Am J Pathol 2006;168:1057-1059. doi: 10.2353/ajpath.2006. 051296.

[3] Wasley A, Grytdal S, Gallagher K. Centers for Disease Control and Prevention (CDC). Surveillance for acute viral hepatitis-United States, 2006. MMWR Surveill Summ 2008;57:1-24.

[4] Raza A, Sood GK. Hepatocellular carcinoma review: current treatment, and evidence-based medicine. World J Gastroenterol 2014;20:4115-4127. doi: 10.3748/wjg.v20.i15.4115.

[5] Sui L, Zhang W, Chen Y, Zheng Y, Wan T, Zhang W, et al. Human membrane protein Tim-3 facilitates hepatitis A virus entry into target cells. Int $\mathrm{J}$ Mol Med 2006;17:1093-1099. doi: 10.3892/ijmm.17.6.1093.

[6] Anderson DA, Ross BC. Morphogenesis of hepatitis A virus: isolation and characterization of subviral particles. J Virol 1990;64:5284-5289.

[7] Beard MR, Cohen L, Lemon SM, Martin A. Characterization of recombinant hepatitis $A$ virus genomes containing exogenous sequences at the $2 A / 2 B$ junction. J Virol 2001;75:1414-1426. doi: 10.1128/JVI.75.3.1414-1426. 2001. 
[8] Cohen L, Bénichou D, Martin A. Analysis of deletion mutants indicates that the $2 \mathrm{~A}$ polypeptide of hepatitis $\mathrm{A}$ virus participates in virion morphogenesis. J Virol 2002;76:7495-7505. doi: 10.1128/JVI.76.15.7495-7505.2002.

[9] Martin A, Bénichou D, Chao SF, Cohen LM, Lemon SM. Maturation of the hepatitis A virus capsid protein VP1 is not dependent on processing by the 3Cpro proteinase. J Virol 1999;73:6220-6227.

[10] Martin A, Escriou N, Chao SF, Girard M, Lemon SM, Wychowski C. Identification and site-directed mutagenesis of the primary $(2 \mathrm{~A} / 2 \mathrm{~B})$ cleavage site of the hepatitis $A$ virus polyprotein: functional impact on the infectivity of HAV RNA transcripts. Virology 1995;213:213-222. doi: 10.1006/viro.1995. 1561.

[11] Martin A, Lemon SM. Hepatitis A virus: from discovery to vaccines. Hepatology 2006;43:S164-S172. doi: 10.1002/hep.21052.

[12] Helle F, Dubuisson J. Hepatitis C virus entry into host cells. Cell Mol Life Sci 2008;65:100-112. doi: 10.1007/s00018-007-7291-8.

[13] Barth H, Liang TJ, Baumert TF. Hepatitis C virus entry: molecular biology and clinical implications. Hepatology 2006;44:527-535. doi: 10.1002/hep. 21321.

[14] Ashfaq UA, Javed T, Rehman S, Nawaz Z, Riazuddin S. An overview of HCV molecular biology, replication and immune responses. Virol J 2011;8:161. doi: $10.1186 / 1743-422 X-8-161$.

[15] El-Hage N, Luo G. Replication of hepatitis C virus RNA occurs in a membranebound replication complex containing nonstructural viral proteins and RNA. J Gen Virol 2003;84:2761-2769. doi: 10.1099/vir.0.19305-0.

[16] Gosert R, Egger D, Lohmann V, Bartenschlager R, Blum HE, Bienz K, et al. Identification of the hepatitis $C$ virus RNA replication complex in Huh-7 cells harboring subgenomic replicons. J Virol 2003;77:5487-5492. doi: 10.1128/JVI.77.9.5487-5492.2003.

[17] Kalia M, Chandra V, Rahman SA, Sehgal D, Jameel S. Heparan sulfate proteoglycans are required for cellular binding of the hepatitis E virus ORF2 capsid protein and for viral infection. J Virol 2009;83:12714-12724. doi: 10.1128/JVI.00717-09.

[18] Zhou Y, Emerson SU. Heat shock cognate protein 70 may mediate the entry of hepatitis E virus into host cells. J Clin Virol 2006;36:S155. doi: 10. 1016/S1386-6532(06)80480-4.

[19] Zheng ZZ, Miao J, Zhao M, Tang M, Yeo AE, Yu H, et al. Role of heat-shock protein 90 in hepatitis E virus capsid trafficking. J Gen Virol 2010;91:17281736. doi: 10.1099/vir.0.019323-0.

[20] Yu H, Li S, Yang C, Wei M, Song C, Zheng Z, et al. Homology model and potential virus-capsid binding site of a putative HEV receptor Grp78. J Mol Model 2011;17:987-995. doi: 10.1007/s00894-010-0794-5.

[21] Cao D, Meng XJ. Molecular biology and replication of hepatitis E virus. Emerg Microbes Infect 2012;1:e17. doi: 10.1038/emi.2012.7.

[22] Ahmad I, Holla RP, Jameel S. Molecular virology of hepatitis E virus. Virus Res 2011;161:47-58. doi: 10.1016/j.virusres.2011.02.011.

[23] Schulze A, Gripon P, Urban S. Hepatitis B virus infection initiates with a large surface protein-dependent binding to heparan sulfate proteoglycans. Hepatology 2007;46:1759-1768. doi: 10.1002/hep.21896.

[24] Glebe D, Bremer CM. The molecular virology of hepatitis B virus. Semin Liver Dis 2013;33:103-112. doi: 10.1055/s-0033-1345717.

[25] Yan H, Zhong G, Xu G, He W, Jing Z, Gao Z, et al. Sodium taurocholate cotransporting polypeptide is a functional receptor for human hepatitis $B$ and D virus. Elife 2012;1:e00049. doi: 10.7554/eLife.00049.

[26] Kann M, Gerlich WH. Effect of core protein phosphorylation by protein kinase $\mathrm{C}$ on encapsidation of RNA within core particles of hepatitis B virus. J Virol 1994;68:7993-8000.

[27] Wittkop L, Schwarz A, Cassany A, Grün-Bernhard S, Delaleau M, Rabe B, et al. Inhibition of protein kinase $C$ phosphorylation of hepatitis $B$ virus capsids inhibits virion formation and causes intracellular capsid accumulation. Cell Microbiol 2010;12:962-975. doi: 10.1111/j.1462-5822.2010. 01444.x.

[28] Beck J, Nassal M. Hepatitis B virus replication. World J Gastroenterol 2007; 13:48-64. doi: 10.3748/wjg.v13.i1.48.

[29] Lamas Longarela O, Schmidt TT, Schöneweis K, Romeo R, Wedemeyer H, Urban S, et al. Proteoglycans act as cellular hepatitis delta virus attachment receptors. PLoS One 2013;8:e58340. doi: 10.1371/journal.pone. 0058340 .

[30] Abbas Z, Afzal R. Life cycle and pathogenesis of hepatitis D virus: A review. World J Hepatol 2013;5:666-675. doi: 10.4254/wjh.v5.i12.666.

[31] Werzberger A, Mensch B, Kuter B, Brown L, Lewis J, Sitrin R, et al. A controlled trial of a formalin-inactivated hepatitis $A$ vaccine in healthy children. N Engl J Med 1992;327:453-457. doi: 10.1056/NEJM199208133270702.

[32] Innis BL, Snitbhan R, Kunasol P, Laorakpongse T, Poopatanakool W, Kozik $\mathrm{CA}$, et al. Protection against hepatitis $\mathrm{A}$ by an inactivated vaccine. JAMA 1994;271:1328-1334. doi: 10.1001/jama.1994.03510410040030.

[33] Midthun K, Ellerbeck E, Gershman K, Calandra G, Krah D, McCaughtry M, et al. Safety and immunogenicity of a live attenuated hepatitis $A$ virus vaccine in seronegative volunteers. J Infect Dis 1991;163:735-739. doi: 10.1093/infdis/163.4.735.
[34] Gerlach JT, Diepolder HM, Zachoval R, Gruener NH, Jung MC, Ulsenheimer A, et al. Acute hepatitis $C$ : high rate of both spontaneous and treatmentinduced viral clearance. Gastroenterology 2003;125:80-88. doi: 10.1016/ S0016-5085(03)00668-1.

[35] European Association for the Study of the Liver. EASL Clinical Practice Guidelines: management of hepatitis C virus infection. J Hepatol 2011; 55:245-264. doi: 10.1016/j.jhep.2011.02.023.

[36] Antaki N, Craxi A, Kamal S, Moucari R, Van der Merwe S, Haffar S, et al. The neglected hepatitis $C$ virus genotypes 4, 5 and 6 : an international consensus report. Liver Int 2010;30:342-355. doi: 10.1111/j.1478-3231.2009. 02188.x.

[37] European Association for Study of Live. EASL recommendations on treatment of hepatitis C 2015. J Hepatol 2015;63:199-236. doi: 10.1016/j.jhep. 2015.03.025.

[38] Gerolami R, Borentain P, Raissouni F, Motte A, Solas C, Colson P. Treatment of severe acute hepatitis E by ribavirin. J Clin Virol 2011;52:60-62. doi: 10. 1016/j.jcv.2011.06.004

[39] Wedemeyer H, Pischke S, Manns MP. Pathogenesis and treatment of hepatitis e virus infection. Gastroenterology 2012;142:1388-1397.e1. doi: 10. 1053/j.gastro.2012.02.014.

[40] Kamar N, Abravanel F, Selves J, Garrouste C, Esposito L, Lavayssière L, et al. Influence of immunosuppressive therapy on the natural history of genotype 3 hepatitis-E virus infection after organ transplantation. Transplantation 2010;89:353-360. doi: 10.1097/TP.0b013e3181c4096c.

[41] Mallet V, Nicand E, Sultanik P, Chakvetadze C, Tessé S, Thervet E, et al. Brief communication: case reports of ribavirin treatment for chronic hepatitis E. Ann Intern Med 2010;153:85-89. doi: 10.7326/0003-4819-153-2201007200-00257.

[42] Kamar N, Rostaing L, Abravanel F, Garrouste C, Lhomme S, Esposito L, et al. Ribavirin therapy inhibits viral replication on patients with chronic hepatitis e virus infection. Gastroenterology 2010;139:1612-1618. doi: 10.1053/j. gastro.2010.08.002.

[43] El Sayed Zaki M, El Razek MM, El Razek HM. Maternal-fetal hepatitis E transmission: is it underestimated? J Clin Transl Hepatol 2014;2:117-123. doi: $10.14218 /$ JCTH.2014.00006.

[44] Khuroo MS, Kamili S, Jameel S. Vertical transmission of hepatitis E virus. Lancet 1995;345:1025-1026. doi: 10.1016/S0140-6736(95)90761-0.

[45] Patra S, Kumar A, Trivedi SS, Puri M, Sarin SK. Maternal and fetal outcomes in pregnant women with acute hepatitis $E$ virus infection. Ann Intern Med 2007;147:28-33. doi: 10.7326/0003-4819-147-1-200707030-00005.

[46] Siebenlist U, Franzoso G, Brown K. Structure, regulation and function of NF-kappa B. Annu Rev Cell Biol 1994;10:405-455. doi: 10.1146/annurev. cb.10.110194.002201.

[47] Liang TJ. Hepatitis B: the virus and disease. Hepatology 2009;49:S13-S21. doi: $10.1002 /$ hep. 22881 .

[48] Dény $P$, Zoulim F. Hepatitis B virus: from diagnosis to treatment. Pathol Biol (Paris) 2010;58:245-253. doi: 10.1016/j.patbio.2010.05.002.

[49] Shiffman ML. Management of acute hepatitis B. Clin Liver Dis 2010;14:7591; viii-ix. doi: 10.1016/j.cld.2009.11.013.

[50] European Association for the Study of the Liver. EASL clinical practice guidelines: Management of chronic hepatitis B virus infection. J Hepatol 2012;57:167-185. doi: 10.1016/j.jhep.2012.02.010.

[51] Terrault NA, Bzowej NH, Chang KM, Hwang JP, Jonas MM, Murad MH, et al. AASLD guidelines for treatment of chronic hepatitis B. Hepatology $2016 ; 63$ : 261-283. doi: 10.1002/hep.28156.

[52] Lau GK, Piratvisuth T, Luo KX, Marcellin P, Thongsawat S, Cooksley G, et al. Peginterferon Alfa-2a, lamivudine, and the combination for $\mathrm{HBeAg}$-positive chronic hepatitis B. N Engl J Med 2005;352:2682-2695. doi: 10.1056/ NEJMoa043470.

[53] Marcellin P, Avila C, Wursthorn K, Chuang WL, Lau GK, Peng CY, et al. Telbivudine (Ldt) Plus Peg-Interferon (Pegifn) in Hbeag-positive chronic hepatitis $\mathrm{B}$ - very potent antiviral efficacy but risk of peripheral neuropathy $(\mathrm{Pn}) . \mathrm{J}$ Hepatol 2010;52:S6-S7. doi: 10.1016/S0168-8278(10)60015-3.

[54] Reijnders JG, Perquin MJ, Zhang N, Hansen BE, Janssen HL. Nucleos(t)ide analogues only induce temporary hepatitis $\mathrm{B}$ e antigen seroconversion in most patients with chronic hepatitis B. Gastroenterology 2010;139:491498. doi: 10.1053/j.gastro.2010.03.059.

[55] Chang TT, Lai CL, Kew Yoon S, Lee SS, Coelho HS, Carrilho FJ, et al. Entecavir treatment for up to 5 years in patients with hepatitis $B$ e antigenpositive chronic hepatitis B. Hepatology 2010;51:422-430. doi: 10.1002/ hep. 23327.

[56] Marcellin P, Buti M, Gane EJ, Krastev Z, Flisiak R, Germanidis G, et al. Five years of treatment with tenofovir DF (TDF) for chronic hepatitis $B(C H B)$ infection is associated with sustained viral suppression and significant regression of histological fibrosis and cirrhosis. Hepatology 2011;54: 1011A-1012A.

[57] Heathcote EJ, Marcellin P, Buti M, Gane E, De Man RA, Krastev Z, et al. Three-year efficacy and safety of tenofovir disoproxil fumarate treatment for chronic hepatitis B. Gastroenterology 2011;140:132-143. doi: 10. 1053/j.gastro.2010.10.011. 
[58] Geier MR, Geier DA, Zahalsky AC. A review of hepatitis B vaccination. Expert Opin Drug Saf 2003;2:113-122. doi: 10.1517/14740338.2.2.113.

[59] Schiff E, Lai CL, Hadziyannis S, Neuhaus P, Terrault N, Colombo M, et al. Adefovir dipivoxil for wait-listed and post-liver transplantation patients with lamivudine-resistant hepatitis B: final long-term results. Liver Transpl 2007;13:349-360. doi: 10.1002/It.20981.

[60] Papatheodoridis GV, Cholongitas E, Archimandritis AJ, Burroughs AK. Current management of hepatitis B virus infection before and after liver transplantation. Liver Int 2009;29:1294-1305. doi: $10.1111 / \mathrm{j} .1478$ 3231.2009.02085.x.

[61] Heidrich B, Manns MP, Wedemeyer $\mathrm{H}$. Treatment options for hepatitis delta virus infection. Curr Infect Dis Rep 2013;15:31-38. doi: 10.1007/s11908012-0307-z.

[62] Debing $Y$, Neyts J, Delang L. The future of antivirals: broad-spectrum inhibitors. Curr Opin Infect Dis 2015;28:596-602. doi: 10.1097/QCO. 0000000000000212.

[63] Jordheim LP, Durantel D, Zoulim F, Dumontet C. Advances in the development of nucleoside and nucleotide analogues for cancer and viral diseases. Nat Rev Drug Discov 2013;12:447-464. doi: 10.1038/nrd4010.

[64] Sluis-Cremer N, Tachedjian G. Mechanisms of inhibition of HIV replication by non-nucleoside reverse transcriptase inhibitors. Virus Res 2008;134:147156. doi: 10.1016/j.virusres.2008.01.002.

[65] Gerber L, Welzel TM, Zeuzem S. New therapeutic strategies in HCV: polymerase inhibitors. Liver Int 2013;33 Suppl 1:85-92. doi: 10.1111/liv. 12068.

[66] Lv Z, Chu Y, Wang Y. HIV protease inhibitors: a review of molecular selectivity and toxicity. HIV AIDS (Auckl) 2015;7:95-104. doi: 10.2147/HIV. S79956.

[67] Patick AK, Binford SL, Brothers MA, Jackson RL, Ford CE, Diem MD, et al. In vitro antiviral activity of $A G 7088$, a potent inhibitor of human rhinovirus $3 C$ protease. Antimicrob Agents Chemother 1999;43:2444-2450.

[68] Göthel SF, Marahiel MA. Peptidyl-prolyl cis-trans isomerases, a superfamily of ubiquitous folding catalysts. Cell Mol Life Sci 1999;55:423-436. doi: 10. $1007 / \mathrm{s} 000180050299$

[69] Kaul A, Stauffer S, Berger C, Pertel T, Schmitt J, Kallis S, et al. Essential role of cyclophilin $A$ for hepatitis $C$ virus replication and virus production and possible link to polyprotein cleavage kinetics. PLoS Pathog 2009;5: e1000546. doi: 10.1371/journal.ppat.1000546.

[70] Coelmont L, Hanoulle X, Chatterji U, Berger C, Snoeck J, Bobardt M, et al. DEB025 (Alisporivir) inhibits hepatitis $C$ virus replication by preventing a cyclophilin A induced cis-trans isomerisation in domain II of NS5A. PLoS One 2010;5:e13687. doi: 10.1371/journal.pone.0013687.

[71] Gamble TR, Vajdos FF, Yoo S, Worthylake DK, Houseweart M, Sundquist WI, et al. Crystal structure of human cyclophilin $A$ bound to the amino-terminal domain of HIV-1 capsid. Cell 1996;87:1285-1294. doi: 10.1016/S00928674(00)81823-1.

[72] Mazzon M, Mercer J. Lipid interactions during virus entry and infection. Cell Microbiol 2014;16:1493-1502. doi: $10.1111 / \mathrm{cmi} .12340$.

[73] Lucas W. Viral capsids and envelopes: Structure and function. eLS 2010. doi: 10.1002/9780470015902.a0001091.pub2.

[74] Markowitz M, Zolopa A, Squires K, Ruane P, Coakley D, Kearney B, et al. Phase I/II study of the pharmacokinetics, safety and antiretroviral activity of tenofovir alafenamide, a new prodrug of the HIV reverse transcriptase inhibitor tenofovir, in HIV-infected adults. J Antimicrob Chemother 2014; 69:1362-1369. doi: 10.1093/jac/dkt532.

[75] Murakami E, Wang T, Park Y, Hao J, Lepist EI, Babusis D, et al. Implications of efficient hepatic delivery by tenofovir alafenamide (GS-7340) for hepatitis B virus therapy. Antimicrob Agents Chemother 2015;59:3563-3569. doi: 10.1128/AAC.00128-15.

[76] Chan HLY, Fung S, Seto WK, Chuang WL, Chen CY, Kim HJ, et al. A phase 3 study of tenofovir alafenamide compared with tenofovir disoproxil fumarate in patients with HBeAg-positive, chronic hepatitis B: week 48 efficacy and safety results. J Hepatol 2016;64:S161. doi: 10.1016/S0168-8278(16) 01669-X.

[77] Buti M, Gane E, Seto WK, Chan HLY, Chuang WL, Stepanova T, et al. A phase 3 study of tenofovir alafenamide compared with tenofovir disoproxil fumarate in patients with $\mathrm{HBeAg-negative,} \mathrm{chronic} \mathrm{hepatitis} \mathrm{B:} \mathrm{week} 48$ efficacy and safety results. J Hepatol 2016;64:S135. doi: 10.1016/S0168-8278(16) 01637-8.

[78] Lai CL, Ahn SH, Lee KS, Um SH, Cho M, Yoon SK, et al. Phase IIb multicentred randomised trial of besifovir (LB80380) versus entecavir in Asian patients with chronic hepatitis B. Gut 2014;63:996-1004. doi: 10.1136/ gutjnl-2013-305138

[79] Yuen MF, Ahn SH, Lee KS, Um SH, Cho M, Yoon SK, et al. Two-year treatment outcome of chronic hepatitis $B$ infection treated with besifovir vs. entecavir: results from a multicentre study. J Hepatol 2015;62:526-532. doi: 10. 1016/j.jhep.2014.10.026.

[80] Volz T, Allweiss L, Ben MBarek M, Warlich M, Lohse AW, Pollok JM, et al. The entry inhibitor Myrcludex-B efficiently blocks intrahepatic virus spreading in humanized mice previously infected with hepatitis B virus. J Hepatol 2013; 58:861-867. doi: 10.1016/j.jhep.2012.12.008.

[81] Maepa MB, Roelofse I, Ely A, Arbuthnot P. Progress and prospects of antiHBV gene therapy development. Int J Mol Sci 2015;16:17589-17610. doi: 10.3390/ijms160817589.

[82] Cradick TJ, Keck K, Bradshaw S, Jamieson AC, McCaffrey AP. Zinc-finger nucleases as a novel therapeutic strategy for targeting hepatitis $B$ virus DNAs. Mol Ther 2010;18:947-954. doi: 10.1038/mt.2010.20.

[83] Chen J, Zhang W, Lin J, Wang F, Wu M, Chen C, et al. An efficient antiviral strategy for targeting hepatitis $\mathrm{B}$ virus genome using transcription activatorlike effector nucleases. Mol Ther 2014;22:303-311. doi: 10.1038/mt. 2013.212.

[84] Makarova KS, Haft DH, Barrangou R, Brouns SJ, Charpentier E, Horvath P, et al. Evolution and classification of the CRISPR-Cas systems. Nat Rev Microbiol 2011;9:467-477. doi: 10.1038/nrmicro2577.

[85] Lin SR, Yang HC, Kuo YT, Liu C], Yang TY, Sung KC, et al. The CRISPR/Cas9 system facilitates clearance of the intrahepatic HBV templates in vivo. Mol Ther Nucleic Acids 2014;3:e186. doi: 10.1038/mtna.2014.38.

[86] Cai D, Mills C, Yu W, Yan R, Aldrich CE, Saputelli JR, et al. Identification of disubstituted sulfonamide compounds as specific inhibitors of hepatitis $B$ virus covalently closed circular DNA formation. Antimicrob Agents Chemother 2012;56:4277-4288. doi: 10.1128/AAC.00473-12.

[87] Katen SP, Chirapu SR, Finn MG, Zlotnick A. Trapping of hepatitis B virus capsid assembly intermediates by phenylpropenamide assembly accelerators. ACS Chem Biol 2010;5:1125-1136. doi: 10.1021/cb100275b.

[88] Wang P, Naduthambi D, Mosley RT, Niu C, Furman PA, Otto MJ, et al. Phenylpropenamide derivatives: anti-hepatitis $B$ virus activity of the $Z$ isomer, SAR and the search for novel analogs. Bioorg Med Chem Lett 2011;21:46424647. doi: $10.1016 / \mathrm{j}$.bmcl.2011.05.077.

[89] Campagna MR, Liu F, Mao R, Mills C, Cai D, Guo F, et al. Sulfamoylbenzamide derivatives inhibit the assembly of hepatitis $B$ virus nucleocapsids. J Virol 2013;87:6931-6942. doi: 10.1128/JVI.00582-13.

[90] Wooddell CI, Rozema DB, Hossbach M, John M, Hamilton HL, Chu Q, et al. Hepatocyte-targeted RNAi therapeutics for the treatment of chronic hepatitis B virus infection. Mol Ther 2013;21:973-985. doi: 10.1038/mt. 2013.31.

[91] Gish RG, Yuen MF, Chan HL, Given BD, Lai CL, Locarnini SA, et al. Synthetic RNAi triggers and their use in chronic hepatitis $B$ therapies with curative intent. Antiviral Res 2015;121:97-108. doi: 10.1016/j.antiviral.2015.06. 019.

[92] Noordeen F, Scougall CA, Grosse A, Qiao Q, Ajilian BB, Reaiche-Miller G, et al. Therapeutic antiviral effect of the nucleic acid polymer REP 2055 against persistent duck hepatitis B virus infection. PLoS One 2015;10: e0140909. doi: 10.1371/journal.pone.0140909.

[93] Hu Y, Cheng X, Cao F, Huang A, Tavis JE. Beta-Thujaplicinol inhibits hepatitis $B$ virus replication by blocking the viral ribonuclease $\mathrm{H}$ activity. Antiviral Res 2013;99:221-229. doi: 10.1016/j.antiviral.2013.06.007.

[94] Lu G, Lomonosova E, Cheng X, Moran EA, Meyers MJ, Le Grice SF, et al. Hydroxylated tropolones inhibit hepatitis $B$ virus replication by blocking viral ribonuclease H activity. Antimicrob Agents Chemother 2015;59: 1070-1079. doi: 10.1128/AAC.04617-14.

[95] Franssen H, Leunissen J, Goldbach R, Lomonossoff G, Zimmern D. Homologous sequences in non-structural proteins from cowpea mosaic virus and picornaviruses. EMBO J 1984;3:855-861.

[96] Gonzalez ME, Carrasco L. Viroporins. FEBS Lett 2003;552:28-34. doi: 10. 1016/S0014-5793(03)00780-4.

[97] Shukla A, Dey D, Banerjee K, Nain A, Banerjee M. The C-terminal region of the non-structural protein 2B from Hepatitis A Virus demonstrates lipidspecific viroporin-like activity. Sci Rep 2015;5:15884. doi: 10.1038/ srep 15884.

[98] Scott C, Griffin S. Viroporins: structure, function and potential as antiviral targets. J Gen Virol 2015;96:2000-2027. doi: 10.1099/vir.0.000201.

[99] OuYang B, Chou J]. The minimalist architectures of viroporins and their therapeutic implications. Biochim Biophys Acta 2014;1838:1058-1067. doi: 10.1016/j.bbamem.2013.09.004.

[100] Furuta A, Tsubuki M, Endoh M, Miyamoto T, Tanaka J, Salam KA, et al. Identification of Hydroxyanthraquinones as novel inhibitors of hepatitis C virus NS3 helicase. Int J Mol Sci 2015;16:18439-18453. doi: 10. 3390/ijms160818439.

[101] Shukla A, Padhi AK, Gomes J, Banerjee M. The VP4 peptide of hepatitis A virus ruptures membranes through formation of discrete pores. J Virol 2014;88:12409-12421. doi: 10.1128/JVI.01896-14.

[102] Liu S, Wei W, Shi K, Cao X, Zhou M, Liu Z. In vitro and in vivo anti-hepatitis B virus activities of the lignan niranthin isolated from Phyllanthus niruri L. J Ethnopharmacol 2014;155:1061-1067. doi: 10.1016/j.jep.2014.05.064.

[103] Jiang $X$, Kanda T, Nakamoto S, Saito K, Nakamura M, Wu S, et al. The JAK2 inhibitor AZD1480 inhibits hepatitis A virus replication in Huh7 cells. Biochem Biophys Res Commun 2015;458:908-912. doi: 10.1016/j.bbrc. 2015.02.058 
[104] Kanda T, Sasaki R, Nakamoto $S$, Haga $Y$, Nakamura M, Shirasawa $H$, et al. The sirtuin inhibitor sirtinol inhibits hepatitis A virus (HAV) replication by inhibiting HAV internal ribosomal entry site activity. Biochem Biophys Res Commun 2015;466:567-571. doi: 10.1016/j.bbrc.2015.09.083.

[105] Koh C, Canini L, Dahari H, Zhao X, Uprichard SL, Haynes-Williams V, et al. Oral prenylation inhibition with lonafarnib in chronic hepatitis $D$ infection: a proof-of-concept randomised, double-blind, placebo-controlled phase 2A trial. Lancet Infect Dis 2015;15:1167-1174. doi: 10.1016/S14733099(15)00074-2.

[106] Lu JX, Sharpe S, Ghirlando R, Yau WM, Tycko R. Oligomerization state and supramolecular structure of the HIV-1 Vpu protein transmembrane segment in phospholipid bilayers. Protein Sci 2010;19:1877-1896. doi: 10.1002/pro.474.

[107] Atoom AM, Taylor NG, Russell RS. The elusive function of the hepatitis C virus p7 protein. Virology 2014;462-463:377-387. doi: 10.1016/j.virol. 2014.04.018.

[108] Pinto LH, Lamb RA. The M2 proton channels of influenza A and B viruses. ] Biol Chem 2006;281:8997-9000. doi: 10.1074/jbc.R500020200.

[109] Ruch TR, Machamer CE. The coronavirus E protein: assembly and beyond. Viruses 2012;4:363-382. doi: 10.3390/v4030363.

[110] Lu W, Zheng B], Xu K, Schwarz W, Du L, Wong CK, et al. Severe acute respiratory syndrome-associated coronavirus $3 a$ protein forms an ion channel and modulates virus release. Proc Natl Acad Sci U S A 2006;103: 12540-12545. doi: 10.1073/pnas.0605402103.

[111] Mehmel M, Rothermel M, Meckel T, Van Etten JL, Moroni A, Thiel G. Possible function for virus encoded $\mathrm{K}+$ channel $\mathrm{Kcv}$ in the replication of chlorella virus PBCV-1. FEBS Lett 2003;552:7-11. doi: 10.1016/S0014-5793(03) 00776-2.

[112] Daniels R, Sadowicz D, Hebert DN. A very late viral protein triggers the Iytic release of SV40. PLoS Pathog 2007;3:e98. doi: 10.1371/journal. ppat.0030098.

[113] van Kuppeveld FJ, Hoenderop JG, Smeets RL, Willems PH, Dijkman HB, Galama JM, et al. Coxsackievirus protein 2B modifies endoplasmic reticulum membrane and plasma membrane permeability and facilitates virus release. EMBO J 1997;16:3519-3532. doi: 10.1093/emboj/16.12.3519.

[114] Martínez-Gil L, Bañó-Polo M, Redondo N, Sánchez-Martínez S, Nieva JL, Carrasco $\mathrm{L}$, et al. Membrane integration of poliovirus 2B viroporin. J Virol 2011;85:11315-11324. doi: 10.1128/JVI.05421-11.

[115] Melton JV, Ewart GD, Weir RC, Board PG, Lee E, Gage PW. Alphavirus 6K proteins form ion channels. J Biol Chem 2002;277:46923-46931. doi: 10. 1074/jbc.M207847200.

[116] Piller SC, Ewart GD, Jans DA, Gage PW, Cox GB. The amino-terminal region of $\mathrm{Vpr}$ from human immunodeficiency virus type 1 forms ion channels and kills neurons. J Virol 1999;73:4230-4238.

[117] Kim JW, Lyi SM, Parrish CR, Parker JS. A proapoptotic peptide derived from reovirus outer capsid protein \{micro\}1 has membrane-destabilizing activity. J Virol 2011;85:1507-1516. doi: 10.1128/JVI.01876-10.

[118] Galloux M, Libersou S, Morellet N, Bouaziz S, Da Costa B, Ouldali M, et al. Infectious bursal disease virus, a non-enveloped virus, possesses a capsidassociated peptide that deforms and perforates biological membranes. J Biol Chem 2007;282:20774-20784. doi: 10.1074/jbc.M701048200. 